\title{
The $\left\{\mathrm{P}_{2} \mathrm{~V}_{3} \mathrm{~W}_{15}\right\}$-Polyoxometalates Functionalized with Phthalocyaninato $\mathrm{Y}$ and $\mathrm{Yb}$ Moieties
}

Ricarda Pütt, ${ }^{a}$ Piotr Kozłowski, ${ }^{b}$ Irina Werner, ${ }^{c}$ Jan Griebel, ${ }^{c}$ Sebastian Schmitz, ${ }^{c}$ Jonas Warneke, ${ }^{c, d}$ and Kirill Yu. Monakhov ${ }^{c, *}$

a Institute of Inorganic Chemistry, RWTH Aachen University, Landoltweg 1, 52074 Aachen, Germany

b Faculty of Physics, Adam Mickiewicz University in Poznań, ul. Uniwersytetu Poznańskiego 2, 61-614 Poznań, Poland

c Leibniz Institute of Surface Engineering (IOM), Permoserstraße 15, 04318 Leipzig, Germany

d Wilhelm-Ostwald-Institute for Physical and Theoretical Chemistry, Leipzig University, Linnéstraße 2, 04103 Leipzig, Germany

Correspondence and requests for materials should be addressed to K.Y.M.

(email: kirill.monakhov@iom-leipzig.de) 


\section{Table of contents}

1. General analytical methods and chemicals S-3

2. Synthesis S-4

3. Infrared (IR) spectra S-6

4. UV/Vis spectra $\quad$ S-7

5. Electrospray ionization (ESI) mass spectrometry data S-8

6. NMR spectra $\quad \mathrm{S}-10$

7. Thermogravimetric data S-13

8. Cyclic voltammetry measurements $\quad \mathrm{S}-14$

9. Magnetochemical modeling S-16

10. References S-19 


\section{General analytical methods and chemicals}

All starting materials were commercial and used as received. Elemental analysis was performed using a Vario EL elemental analyzer. ${ }^{1} \mathrm{H}-,{ }^{31} \mathrm{P}$ - and ${ }^{51} \mathrm{~V}-\mathrm{NMR}$ spectra were recorded on a Bruker $400 \mathrm{MHz}$ spectrometer at room temperature using $\mathrm{CD}_{3} \mathrm{CN}$ and DMSO$d_{6}$ as solvents. Chemical shifts $(\delta)$ are given in ppm. IR spectra were recorded on a Nicolet Avatar $360 \mathrm{FTIR}$ spectrometer by using $\mathrm{KBr}$ pellets $\left(m_{\mathrm{KBr}} \approx 250 \mathrm{mg}\right)$ in the $4000-400 \mathrm{~cm}^{-1}$ range. UV/Vis spectra were recorded on a Shimadzu UV-2600 spectrophotometer. The samples were dissolved in dry acetonitrile and measured in quartz cuvettes $(d=1 \mathrm{~cm})$. EPR spectra were measured on an ELEXSYS EPR spectrometer from BRUKER (X-Band, $B_{0}$ : $100-500 \mathrm{mT}$ ) at room temperature and at $77 \mathrm{~K}$ using a finger Dewar. Cyclovoltammetry was performed using SP-50 potentiostat / galvanostat / Bio Logic Science Instruments with a three-electrode system under nitrogen atmosphere in a deoxygenated anhydrous acetonitrile solution of tetraethylammonium hexafluorophosphate $(0.1 \mathrm{M})$ at $25^{\circ} \mathrm{C}$. Electrode material for the working and counter electrode was platinum, and an $\mathrm{Ag} / \mathrm{Ag}^{+}$electrode was used as the reference electrode. The system was calibrated with ferrocene / ferrocenium $\left(\mathrm{Fc} / \mathrm{Fc}^{+}\right)$. Thermogravimetric analysis was performed with a Perkin Elmer TGA / Pyris 1 TGA under $\mathrm{N}_{2}$ atmosphere and air with a heating rate of $10 \mathrm{~K} \mathrm{~min}^{-1}$. 


\section{Synthesis}

\section{$\left(n \mathrm{Bu}_{4} \mathrm{~N}\right)_{5}[\mathrm{WD}]$}

$\left(n \mathrm{Bu}_{4} \mathrm{~N}\right)_{5}\left[\mathrm{H}_{4} \mathrm{P}_{2} \mathrm{~V}_{3} \mathrm{~W}_{15} \mathrm{O}_{62}\right]$ was prepared according to the literature procedure published by Finke et al. ${ }^{1}$

\section{2-(Hydroxymethyl)-2-(pyridin-4-yl)propan-1,3-diole ${ }^{2}$ (1)}

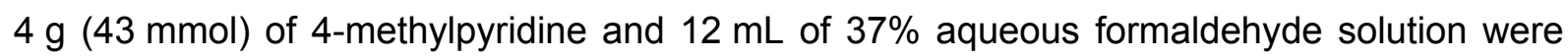
placed in an autoclave with an approximately $20 \mathrm{~mL}$ PTFE crucible and heated at $100{ }^{\circ} \mathrm{C}$ for $40 \mathrm{~h}$. After cooling down to room temperature $10 \mathrm{~mL}$ of $\mathrm{H}_{2} \mathrm{O}$ was given to the reaction mixture to distill out the excess of 4-methylpyridine (repeat four times). Next, $15 \mathrm{~mL}$ of EtOH was added and the reaction mixture was refluxed for $10 \mathrm{~min}$. It was cooled slowly down to room temperature and then put in the refrigerator. After a few days a light-yellow (nearly white) product could be filtered off and dried under high vacuum.

Yield: $945 \mathrm{mg}(12 \%)$.

${ }^{1} \mathrm{H}-\mathrm{NMR}$ (400 MHz, DMSO- $\left.d_{6}, \mathrm{ppm}\right): \delta=8.43-8.37$ (d, $2 H$ ), 7.40-7.30 (d, 2H), 4.55 (s, 3H), $3.69(d, 6 H)$.

\section{$\left(n \mathrm{Bu}_{4} \mathrm{~N}\right)_{6}[\mathrm{WD}-\mathrm{Py}]$}

\section{$\left.\left(n \mathrm{Bu}_{4} \mathrm{~N}\right)_{6}\left[\mathrm{P}_{2} \mathrm{~V}_{3} \mathrm{~W}_{15} \mathrm{O}_{59}\left(\mathrm{OCH}_{2}\right)_{3} \mathrm{CC}_{5} \mathrm{H}_{4} \mathrm{~N}\right)\right]$}

$1 \mathrm{~g}(0.2 \mathrm{mmol}, 1$ eq. $)$ of $\left(n \mathrm{Bu}_{4} \mathbf{N}\right)_{5}[\mathbf{W D}]$ and $36.64 \mathrm{mg}(0.2 \mathrm{mmol}, 1$ eq. $)$ of 1 were dissolved in $10 \mathrm{~mL}$ of $\mathrm{MeCN}$ under nitrogen atmosphere. The solution was refluxed for 3 days at $85^{\circ} \mathrm{C}$, filtered off and the solvent was reduced on a rotary evaporator to half the volume. The solution was precipitated in $100 \mathrm{~mL}$ of $\mathrm{Et}_{2} \mathrm{O}$ and a yellow solid was obtained. The solid was filtered off, washed with $\mathrm{Et}_{2} \mathrm{O}$ and dried in a desiccator.

Yield: $846 \mathrm{mg}(76 \%)$.

CHN (\%) calcd. for $\mathrm{C}_{105} \mathrm{H}_{226} \mathrm{~N}_{7} \mathrm{O}_{62} \mathrm{P}_{2} \mathrm{~V}_{3} \mathrm{~W}_{15}\left(M=5551.32 \mathrm{~g} \mathrm{~mol}^{-1}\right)$ : C 22.72, H 4.10, N 1.77. Found: C 22.98, H 4.14, N 1.80.

FT-IR (KBr, cm-1): $\tilde{v}=3441(\mathrm{w}), 2960(\mathrm{~m}), 2933(\mathrm{~m}), 2871(\mathrm{~m}), 1633(\mathrm{w}), 1595(\mathrm{w}), 1483(\mathrm{~m})$, $1467(\mathrm{~m}), 1383$ (w), 1087 (s), 949 (vs), 909 (vs), 816 (vs), 732 (vs), 661(w) 597 (w), $527(w)$, $480(w)$.

${ }^{1} \mathrm{H}-\mathrm{NMR}\left(400 \mathrm{MHz}, \mathrm{CD}_{3} \mathrm{CN}, \mathrm{ppm}\right): \delta=8.61(\mathrm{~d}, J=5.2 \mathrm{~Hz}, 2 H), 7.51(\mathrm{~d}, J=5.0 \mathrm{~Hz}, 2 H), 5.61$ (s, 6H), 3.26-3.03 (m, 48H), $1.58(\mathrm{t}, J=8.4 \mathrm{~Hz}, 48 H), 1.33(\mathrm{q}, J=7.3 \mathrm{~Hz}, 48 H), 0.94(\mathrm{t}, J=$ $7.3 \mathrm{~Hz}, 72 H)$.

${ }^{31}$ P-NMR (162 MHz, $\left.\mathrm{CD}_{3} \mathrm{CN}, \mathrm{ppm}\right): \delta=-7.54,-13.67$.

51V-NMR (105 MHz, $\mathrm{CD}_{3} \mathrm{CN}, \mathrm{ppm}$ ): $\delta=-544$. 


\section{$\left(n \mathrm{Bu}_{4} \mathrm{~N}\right)_{4}[\mathrm{HWD}-\mathrm{Py}(\mathrm{MPc})]$}

$\left.\left(n \mathrm{Bu}_{4} \mathrm{~N}\right)_{4}\left[\mathrm{HP}_{2} \mathrm{~V}_{3} \mathrm{~W}_{15} \mathrm{O}_{59}\left(\mathrm{OCH}_{2}\right)_{3} \mathrm{CC}_{5} \mathrm{H}_{4} \mathrm{~N}\right)\left(\mathrm{C}_{32} \mathrm{H}_{16} \mathrm{~N}_{8} \mathrm{M}\right)\right]$ where $\mathrm{M}=\mathrm{Y}^{\prime \prime \prime}$ or $\mathrm{Yb}^{\text {III }}$

In a round-bottom flask, $\left(n \mathrm{Bu}_{4} \mathrm{~N}\right)_{6}[\mathrm{WD}-\mathrm{Py}](100 \mathrm{mg}, 0.018 \mathrm{mmol})$ and $\mathrm{MPc}(\mathrm{OAc}) \cdot 2 \mathrm{MeOH}$ $(0.018 \mathrm{mmol})$ were dissolved in $5 \mathrm{~mL}$ of $\mathrm{MeCN}$ in a $1: 1$ ratio and stirred at room temperature for two days. The dark blue / turquoise solution was filtered off and washed with $2 \mathrm{~mL}$ of $\mathrm{MeCN}$. The filtrate was dropped into $40 \mathrm{~mL}$ of $\mathrm{Et}_{2} \mathrm{O}$, which afforded a turquoise solid. The solid was centrifuged off and washed twice with $30 \mathrm{~mL}$ of $\mathrm{Et}_{2} \mathrm{O}$. The solid was first dried in air and then in a desiccator.

Yield for $\mathbf{M}=\mathbf{Y}: 98.89 \mathrm{mg}(93 \%)$.

CHN (\%) calcd. for $\mathrm{C}_{105} \mathrm{H}_{171} \mathrm{~N}_{13} \mathrm{O}_{62} \mathrm{P}_{2} \mathrm{~V}_{3} \mathrm{~W}_{15} \mathrm{Y} \cdot 2 \mathrm{Et}_{2} \mathrm{O}\left(\mathrm{M}=5817.08 \mathrm{~g} \mathrm{~mol}^{-1}\right)$ : C 23.33, H 3.31, N 3.13. Found: C 23.22, H 3.36, N 3.07.

FT-IR $\left(\mathrm{KBr}, \mathrm{cm}^{-1}\right): \tilde{v}=3439(\mathrm{w}), 2960(\mathrm{~m}), 2930(\mathrm{~m}), 2871(\mathrm{~m}), 1638(\mathrm{w}), 1595(\mathrm{w}), 1483(\mathrm{~m})$, $1459(\mathrm{~m}), 1383(\mathrm{w}), 1329(\mathrm{w}), 1283(\mathrm{~m}), 1160(\mathrm{w}), 1113(\mathrm{~m}), 1085(\mathrm{~s}), 1062(\mathrm{~m}), 952(\mathrm{~s}), 909$ (s), 812 (vs), 732 (vs), $598(\mathrm{~m}), 527(\mathrm{~m}), 480(\mathrm{~m})$.

${ }^{1} \mathrm{H}-\mathrm{NMR}\left(400 \mathrm{MHz}, \mathrm{DMSO}-d_{6}, \mathrm{ppm}\right): \delta=9.46-9.24(\mathrm{~m}, 8 H), 8.57(\mathrm{~d}, 2 H), 8.22-8.07(\mathrm{~m}, 8 H)$, $7.42(\mathrm{~d}, J=6.0 \mathrm{~Hz}, 2 H), 5.60(\mathrm{~s}, 6 H)$.

${ }^{31}$ P-NMR (162 MHz, DMSO- $\left.d_{6}, \mathrm{ppm}\right): \delta=-7.59,-13.73$.

51V-NMR (105 MHz, DMSO- $\left.d_{6}, \mathrm{ppm}\right): \delta=-543$.

UV/Vis (MeCN, nm): $\lambda=242,266,334,612,648,678,832$.

Yield for $\mathbf{M}=\mathbf{Y b}: 94.42 \mathrm{mg}(90 \%)$.

CHN (\%) calcd. for $\mathrm{C}_{105} \mathrm{H}_{171} \mathrm{~N}_{13} \mathrm{O}_{62} \mathrm{P}_{2} \mathrm{~V}_{3} \mathrm{~W}_{15} \mathrm{Yb} \cdot 2 \mathrm{Et}_{2} \mathrm{O}\left(M=5901.22 \mathrm{~g} \mathrm{~mol}^{-1}\right)$ : C 23.00, H 3.26, N 3.09. Found: C 23.03, H 3.28, N 3.12.

FT-IR (KBr, cm$\left.{ }^{-1}\right): \tilde{v}=3441(\mathrm{w}), 2960(\mathrm{~m}), 2930(\mathrm{~m}), 2871(\mathrm{~m}), 1635(\mathrm{w}), 1594(\mathrm{w}), 1485(\mathrm{~m})$, $1459(\mathrm{~m}), 1407$ (w), 1380 (w), 1329 (s), $1284(\mathrm{~m}), 1163(\mathrm{w}), 1114 / \mathrm{m}), 1085$ (s), 1062 (s), 953 (vs), 909 (vs), 809 (vs), 729 (vs), 630 (m), 598 (m), 528 (m), 480 (m).

UV/Vis (MeCN, nm): $\lambda=242,266,332,614,650,682,832$.

Table S1. Values (calcd. (found)) obtained from elemental analysis of the compounds $\left(n \mathrm{Bu}_{4} \mathrm{~N}\right)_{6}[\mathbf{W D}-\mathbf{P y}]$ and $\left(n \mathrm{Bu}_{4} \mathrm{~N}\right)_{4}[\mathrm{HWD}-\mathbf{P y}(\mathrm{YPc})] \cdot 2 \mathrm{Et}_{2} \mathrm{O}$.

\begin{tabular}{lccc}
\hline \multicolumn{1}{c}{ Compound } & $\mathrm{C}$ & $\mathrm{H}$ & $\mathrm{N}$ \\
\hline$\left(n \mathrm{Bu}_{4} \mathrm{~N}\right)_{6}[\mathbf{W D}-\mathrm{Py}]$ & $22.71(22.98)$ & $4.10(4.14)$ & $1.77(1.80)$ \\
$\left(n \mathrm{Bu}_{4} \mathrm{~N}\right)_{4}[\mathrm{HWD}-\mathrm{Py}(\mathrm{YPc})] \cdot 2 \mathrm{Et}_{2} \mathrm{O}$ & $23.33(23.22)$ & $3.31(3.36)$ & $3.13(3.07)$ \\
$\left(n \mathrm{Bu}_{4} \mathrm{~N}\right)_{4}[\mathrm{HWD}-\mathrm{Py}(\mathrm{YbPc})] \cdot 2 \mathrm{Et}_{2} \mathrm{O}$ & $23.00(23.03)$ & $3.26(3.28)$ & $3.09(3.12)$ \\
\hline
\end{tabular}




\section{Infrared (IR) spectra}

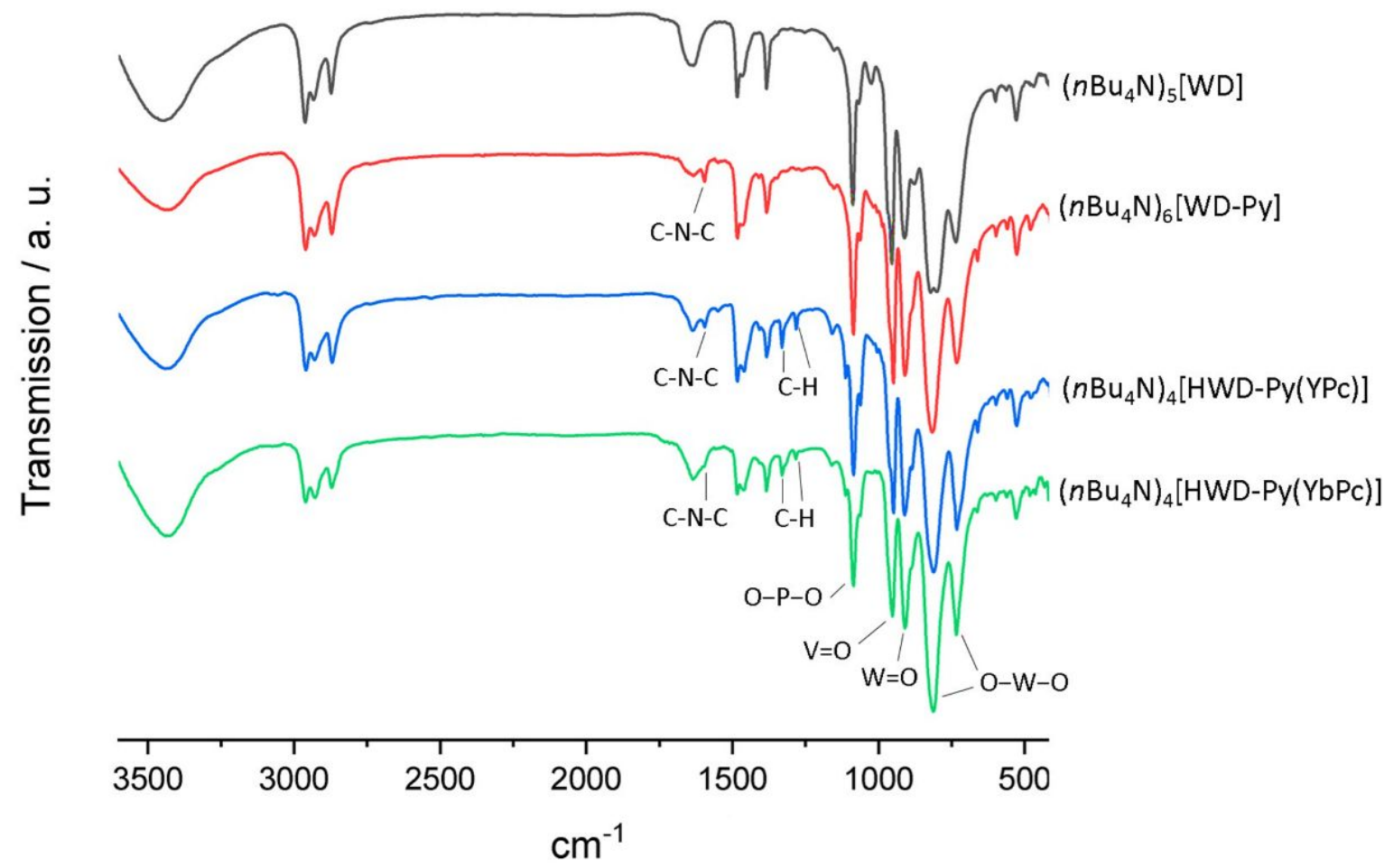

Figure S1. IR spectra of $\left(n \mathrm{Bu}_{4} \mathrm{~N}\right)_{5}[\mathbf{W D}],\left(n \mathrm{Bu}_{4} \mathrm{~N}\right)_{6}[\mathbf{W D}-\mathrm{Py}],\left(n \mathrm{Bu}_{4} \mathrm{~N}\right)_{4}[\mathrm{HWD}-\mathrm{Py}(\mathrm{YPc})]$ and $\left(n \mathrm{Bu}_{4} \mathrm{~N}\right)_{4}[\mathrm{HWD}-\mathrm{Py}(\mathrm{YbPc})]$ in the $3500-500 \mathrm{~cm}^{-1}$ region. 


\section{UV/Vis spectra}

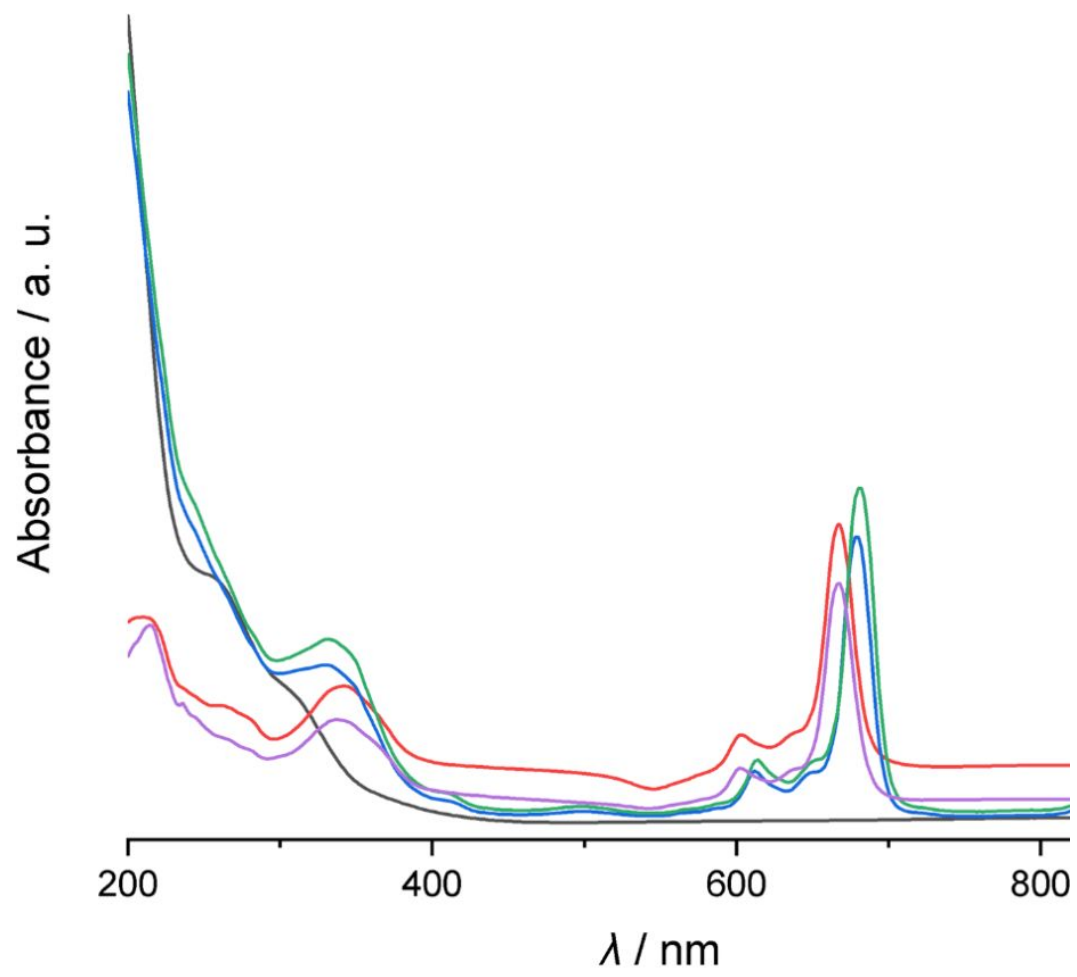

Figure S2. UV/Vis spectra of $\left(n \mathrm{Bu}_{4} \mathrm{~N}\right)_{6}[\mathrm{WD}-\mathrm{Py}]\left(c=4 \times 10^{-6}\right.$, black curve), $\mathrm{YPc}(\mathrm{OAc}) \cdot 2 \mathrm{MeOH}$ $\left(c=2 \times 10^{-5}\right.$, purple), $\quad \mathrm{YbPc}(\mathrm{OAc}) \cdot 2 \mathrm{MeOH} \quad\left(c=2 \times 10^{-5}, \quad\right.$ red $), \quad\left(n \mathrm{Bu}_{4} \mathrm{~N}\right)_{4}[\mathrm{HWD}-\mathrm{Py}(\mathrm{YPc})]$ $\left(c=4 \times 10^{-6}\right.$, blue), and $\left(n \mathrm{Bu}_{4} \mathrm{~N}\right)_{4}[\mathrm{HWD}-\mathrm{Py}(\mathrm{YbPc})]\left(c=4 \times 10^{-6}\right.$, green $)$ in the $200-800 \mathrm{~nm}$ range in $\mathrm{MeCN}$. 


\section{Electrospray ionization (ESI) mass spectrometry data}

Mass spectrometry measurements were performed on a Thermo LTQ Orbitrap XL (Thermo Fisher Scientific $\mathrm{GmbH}$, Bremen, Germany) under the following instrument conditions: electrospray voltage: $-2.7 \mathrm{kV}$, capillary temperature: $270^{\circ} \mathrm{C}$, capillary voltage: $-37 \mathrm{~V}$, tube lens: $-90 \mathrm{~V}$. Samples were dissolved in acetonitrile (around $10^{-6} \mathrm{~mol} \mathrm{~L}^{-1}$ ) and injected via a syringe pump at a flow rate of $5 \mathrm{~mL} \mathrm{~min}{ }^{-1}$. High resolution measurements were carried out in five steps from $\mathrm{m} / \mathrm{z}$ 1000-3000 (each spectrum covering a range $400 \mathrm{~m} / \mathrm{z}$-units). Mass calibration was performed externally, using a $\mathrm{K}_{2}\left[\mathrm{~B}_{12} \mathrm{l}_{12}\right]$ solution which generates a variety of known ions within this mass range upon collision induced excitation. ${ }^{3}$

The data shown in Figure 2 of the manuscript provide strong evidence that the targeted molecular structures are present in solution. It should be notified that several isotopologes contribute to all signals with relevant intensity. Usually, molecular formula assignment is performed using the signal of an accurate mass measurements of the "monoisotopic" ions at smallest $\mathrm{m} / \mathrm{z}$ of an isotopic pattern. This signal is not measurable in the isotopic pattern of the discussed compounds due to its negligible natural abundance. However, a comparison of the measured signals with a simulated pattern showed very good agreement. A "zoom-in" of Figure 2 is shown in Figure S3. Note that it is however not unambiguously possible with mass resolution and accuracy available for us to determine the exact numbers of hydrogens in the molecular formula.
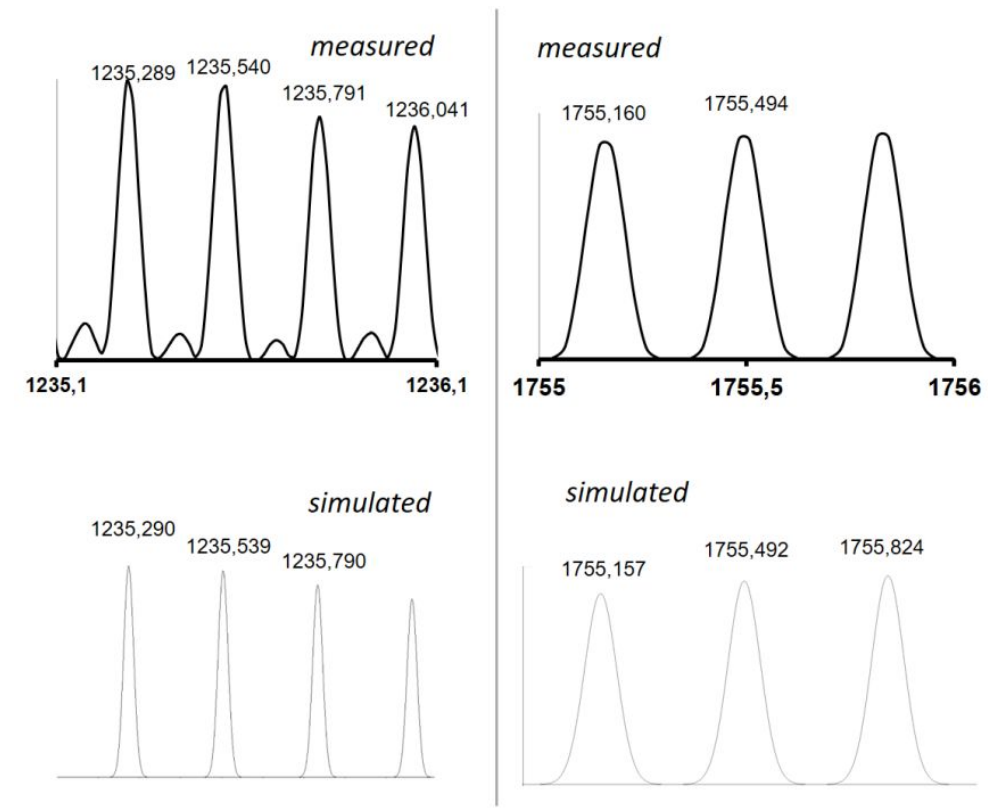

Figure S3. "Zoom in" into the spectra shown in Figure 3. Left: Figure 3a, Right: Figure 3b. Next to the signals shown in Figure 2, several other abundant signals have been detected. These could be partially identified as WD units without the Pc ligand, see Figure S4. 


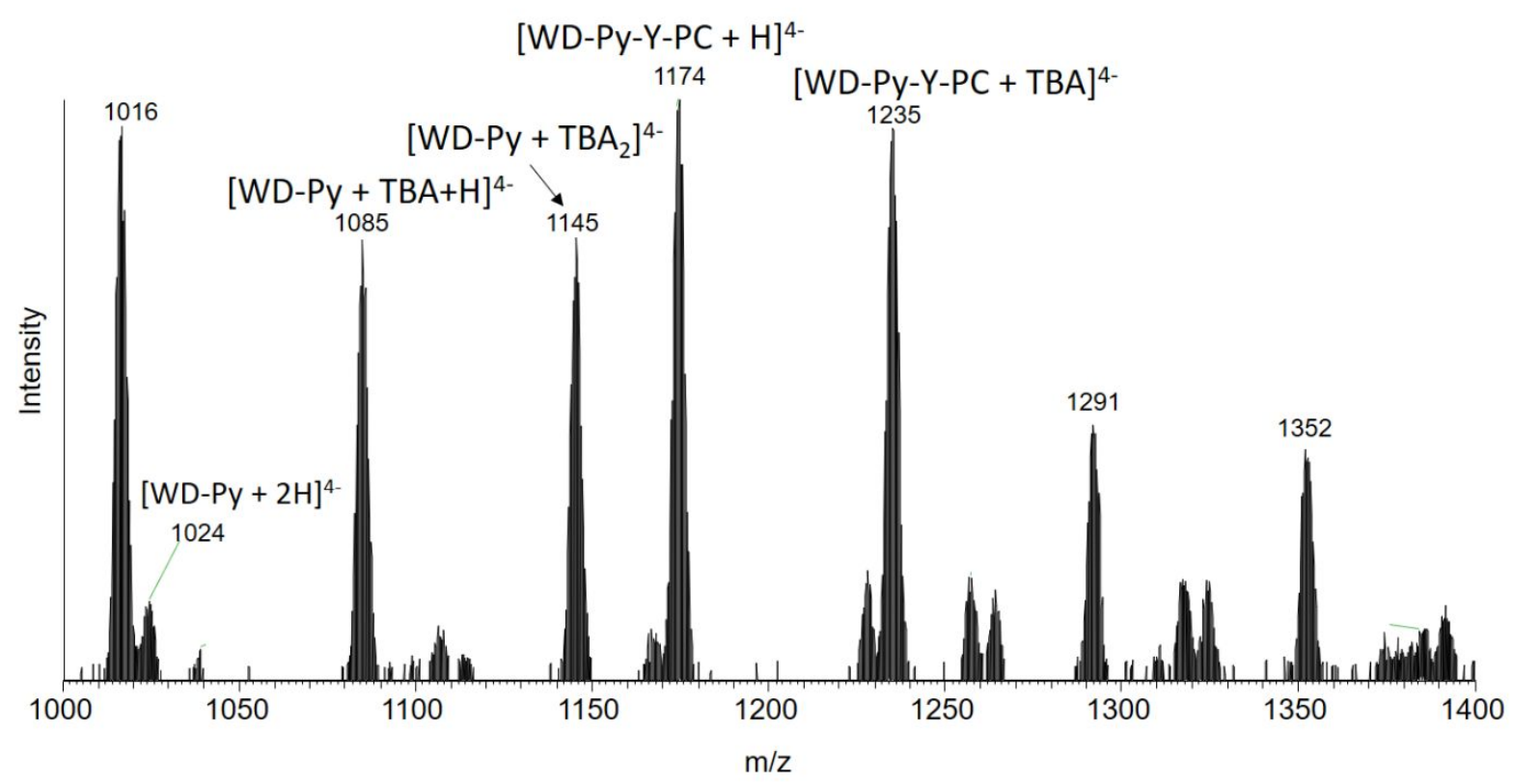

Figure S4. ESI mass spectrum obtained after dissolving the $\left(n \mathrm{Bu}_{4} \mathrm{~N}\right)_{4}[\mathrm{HWD}-\mathrm{Py}(\mathrm{YPc})]$ sample in acetonitrile. 


\section{NMR spectra}

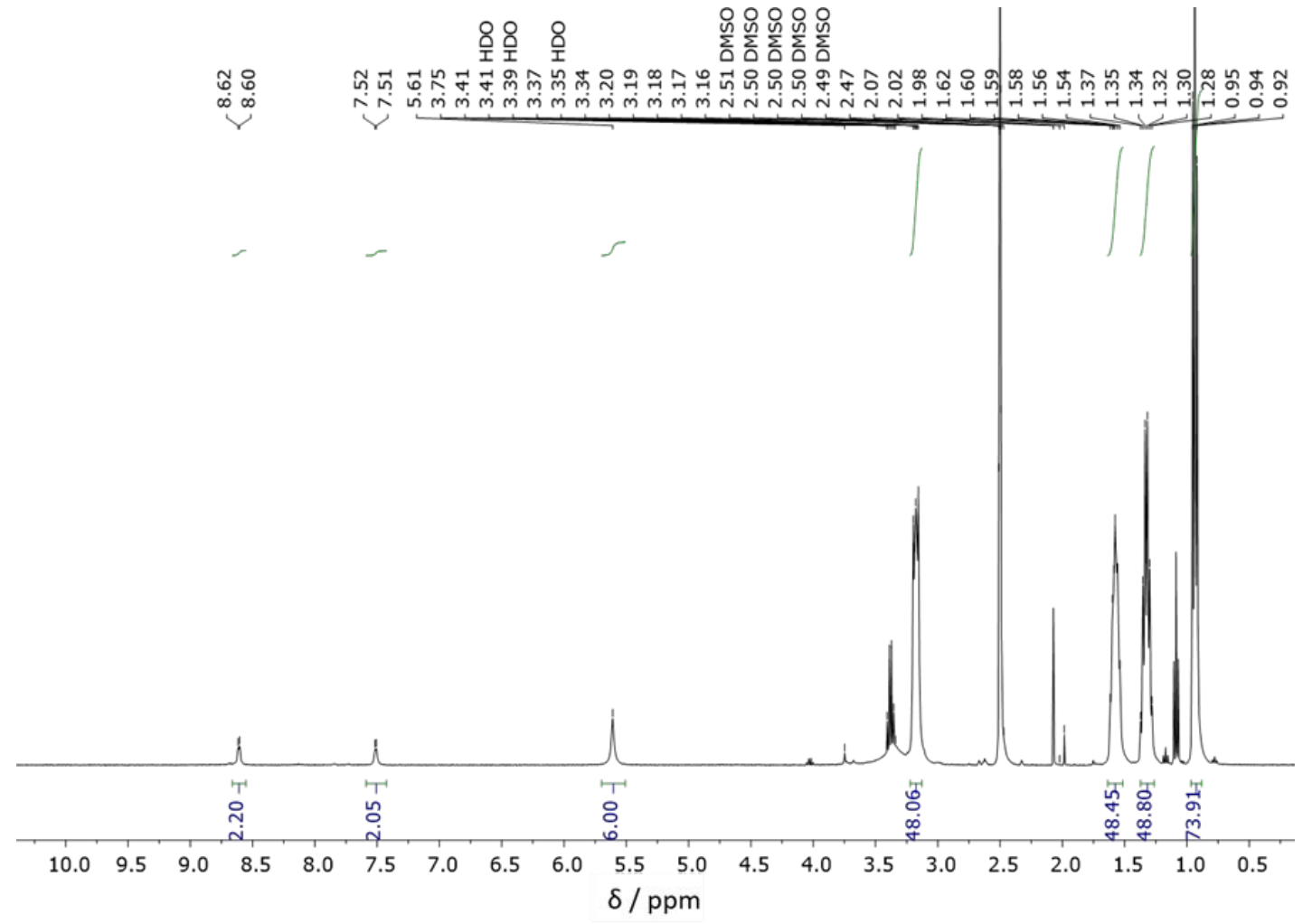

Figure S5. ${ }^{1} \mathrm{H}$ NMR of $\left(n \mathrm{Bu}_{4} \mathrm{~N}\right)_{6}[\mathrm{WD}-\mathrm{Py}]$ in DMSO- $d_{6}$.

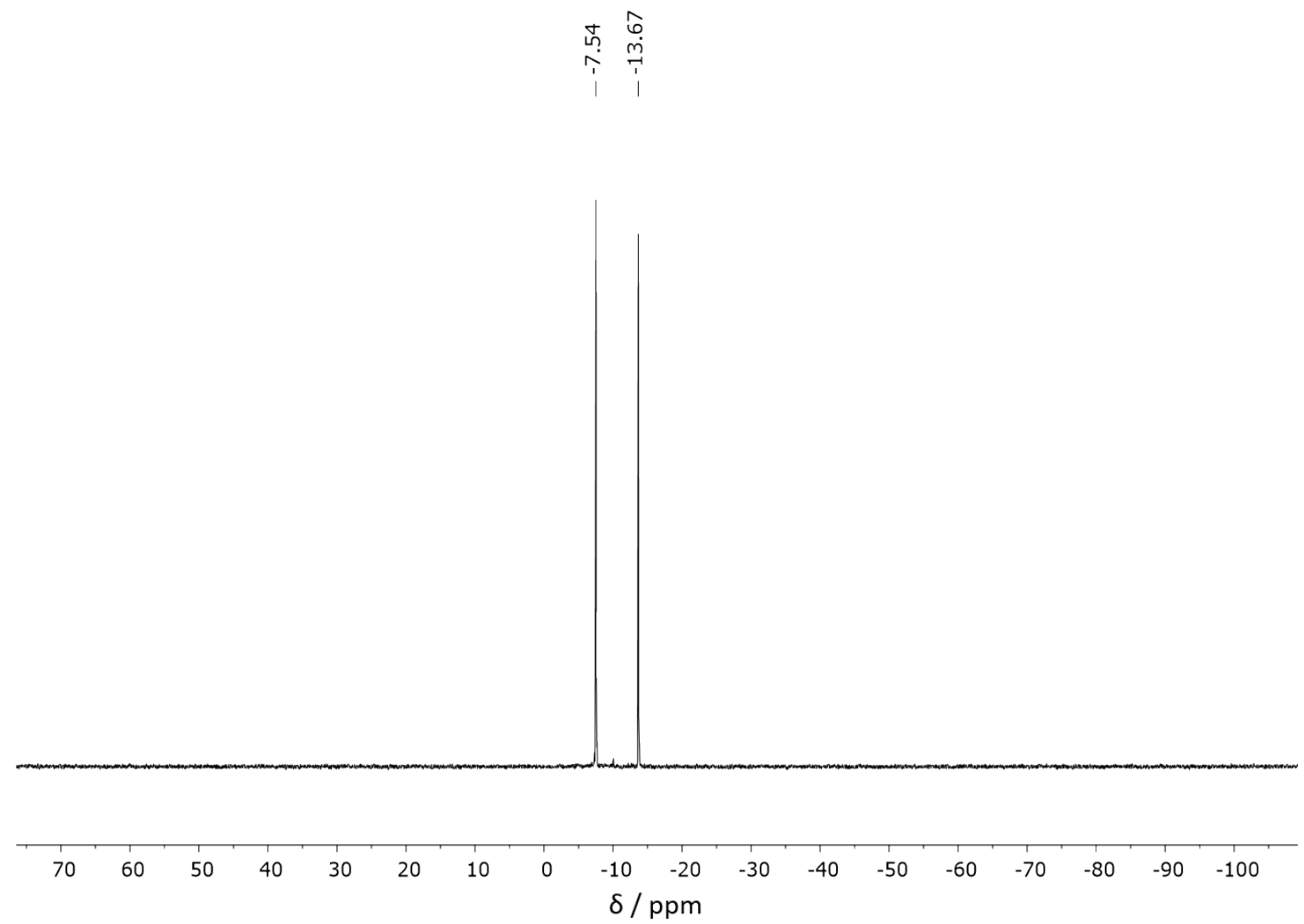

Figure S6. ${ }^{31} \mathrm{P}$ NMR of $\left(n \mathrm{Bu}_{4} \mathrm{~N}\right)_{6}\left[\right.$ WD-Py] in DMSO- $d_{6}$. 


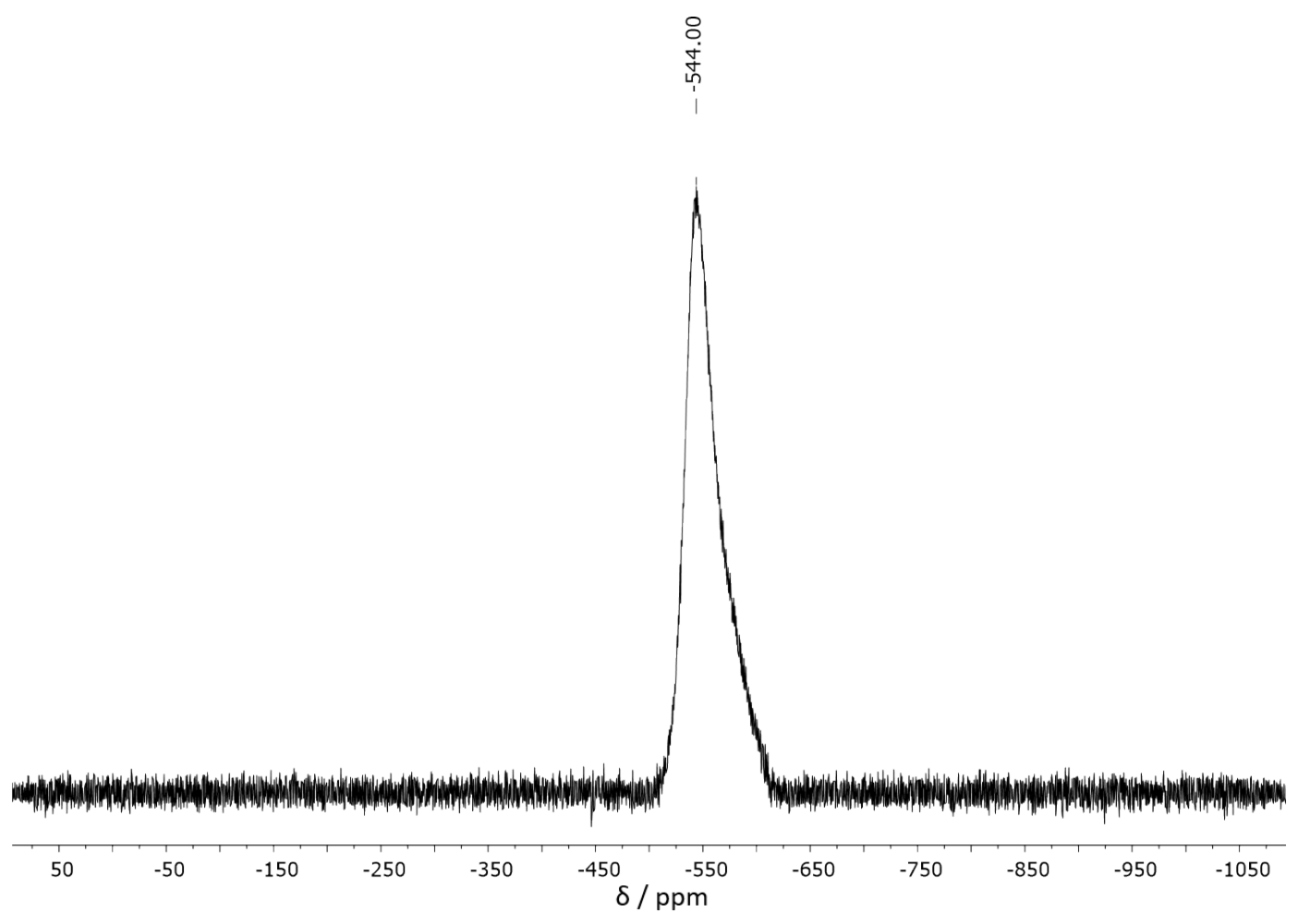

Figure S7. ${ }^{51} \mathrm{~V}$ NMR of $\left(n \mathrm{Bu}_{4} \mathrm{~N}\right)_{6}\left[\right.$ WD-Py] in DMSO- $d_{6}$.

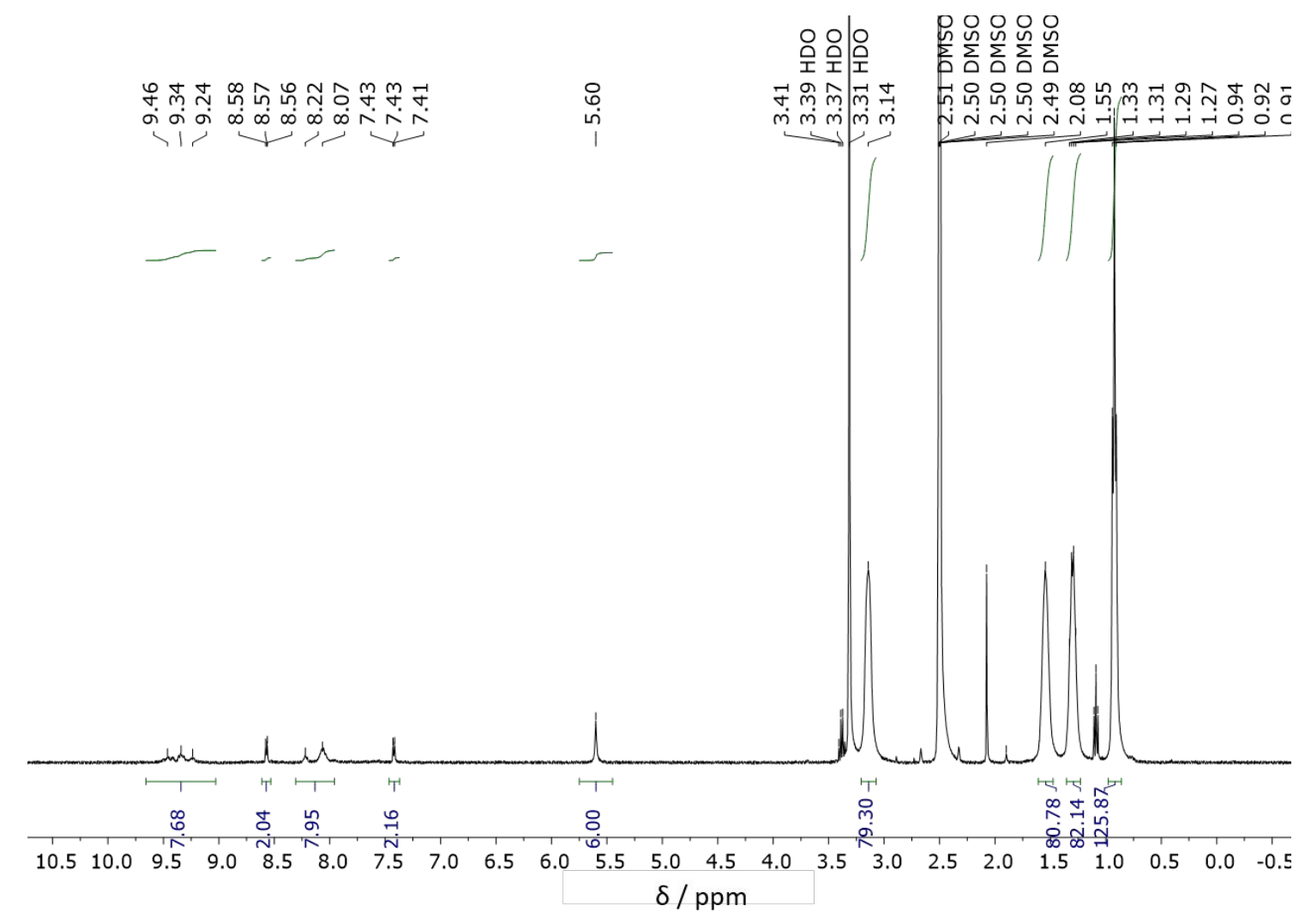

Figure S8. ${ }^{1} \mathrm{H}$ NMR of $\left(n \mathrm{Bu}_{4} \mathrm{~N}\right)_{4}[\mathrm{HWD}-\mathrm{Py}(\mathrm{YPc})]$ in DMSO- $d_{6}$. 


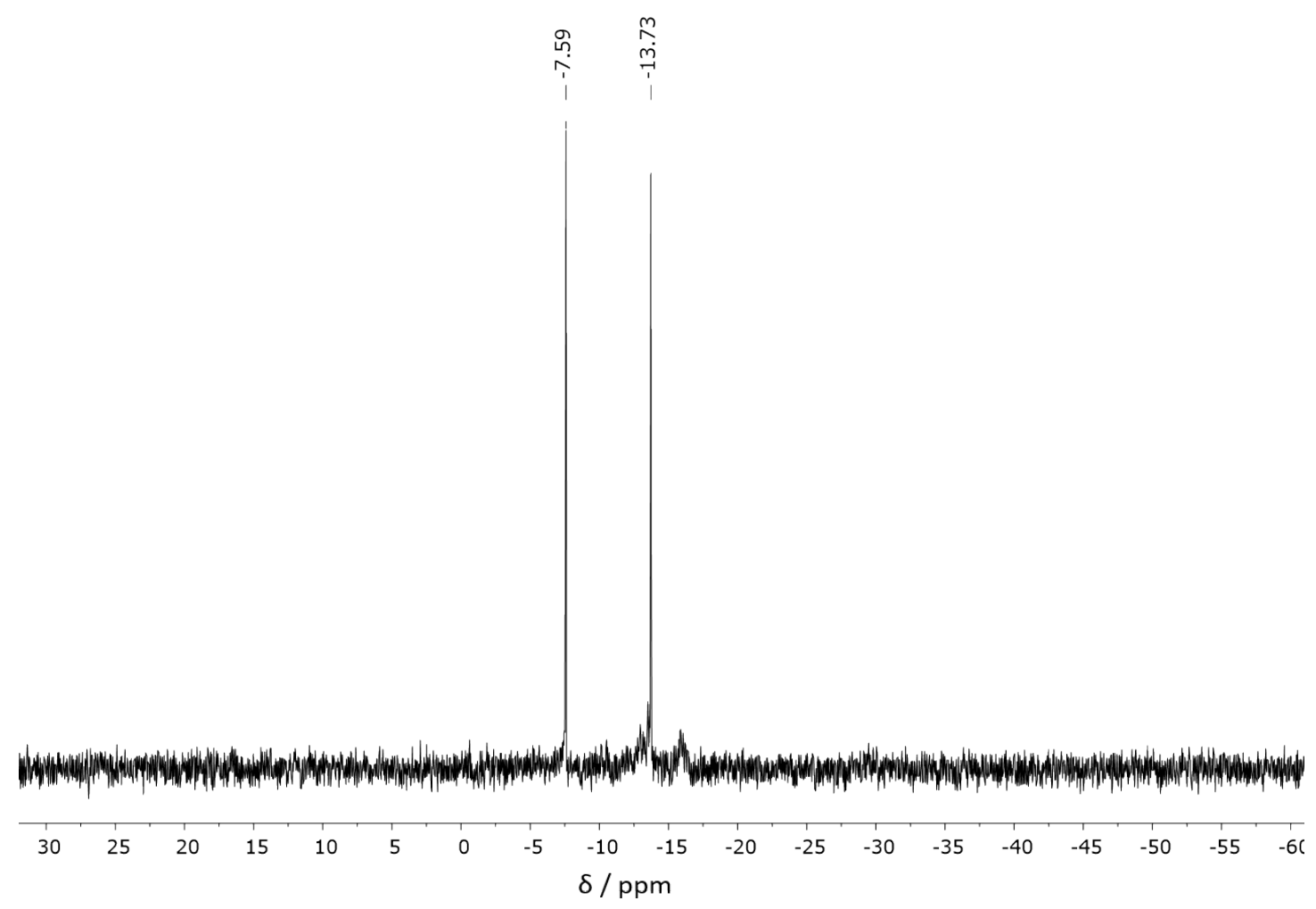

Figure S9. ${ }^{31} \mathrm{P} \mathrm{NMR}$ of $\left(n \mathrm{Bu}_{4} \mathrm{~N}\right)_{4}[\mathrm{HWD}-\mathrm{Py}(\mathrm{YPc})]$ in $\mathrm{DMSO}-d_{6}$.

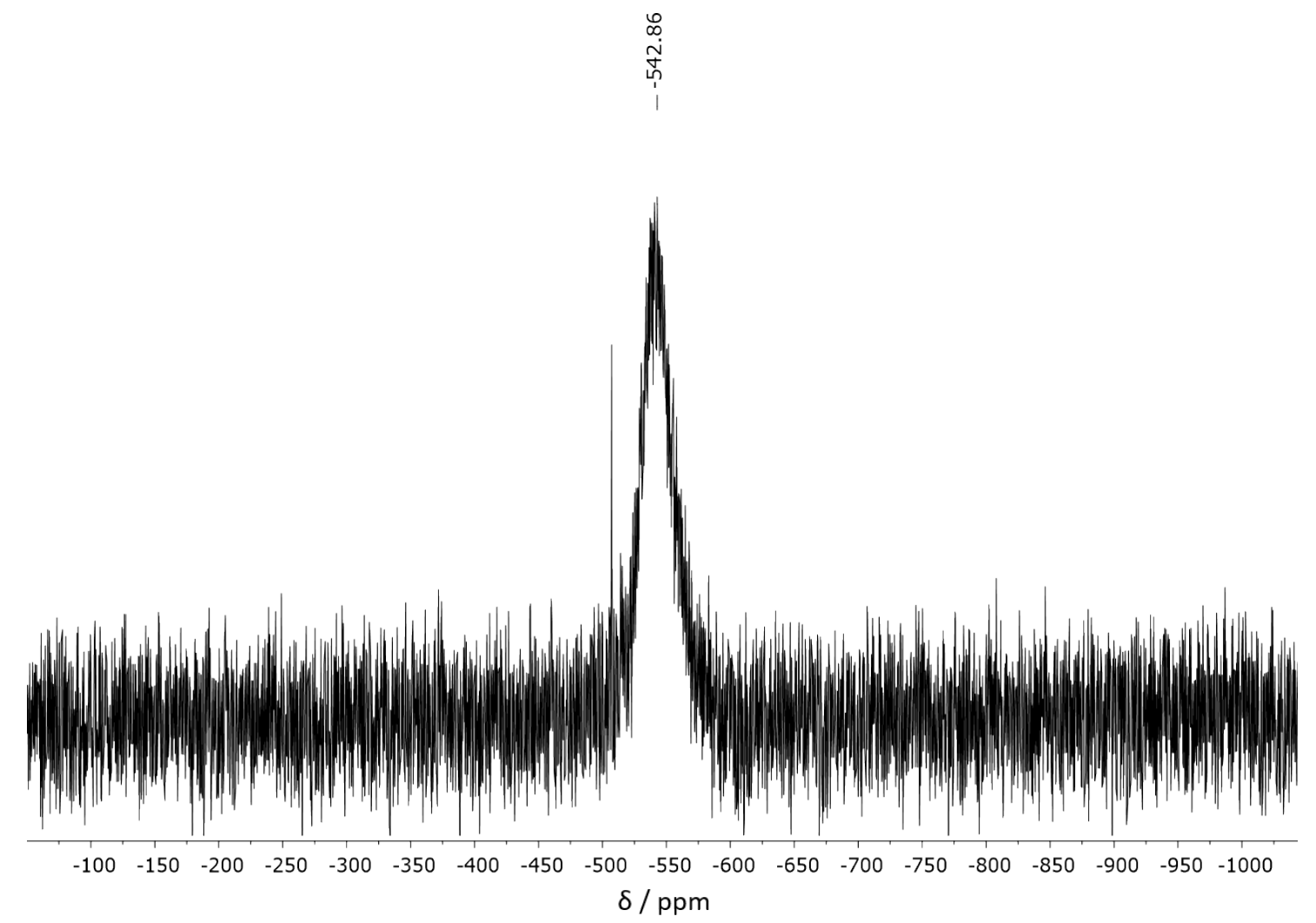

Figure S10. ${ }^{51} \mathrm{~V}$ NMR of $\left(n \mathrm{Bu}_{4} \mathrm{~N}\right)_{4}[\mathrm{HWD}-\mathrm{Py}(\mathrm{YPc})]$ in DMSO- $d_{6}$. 


\section{Thermogravimetric data}

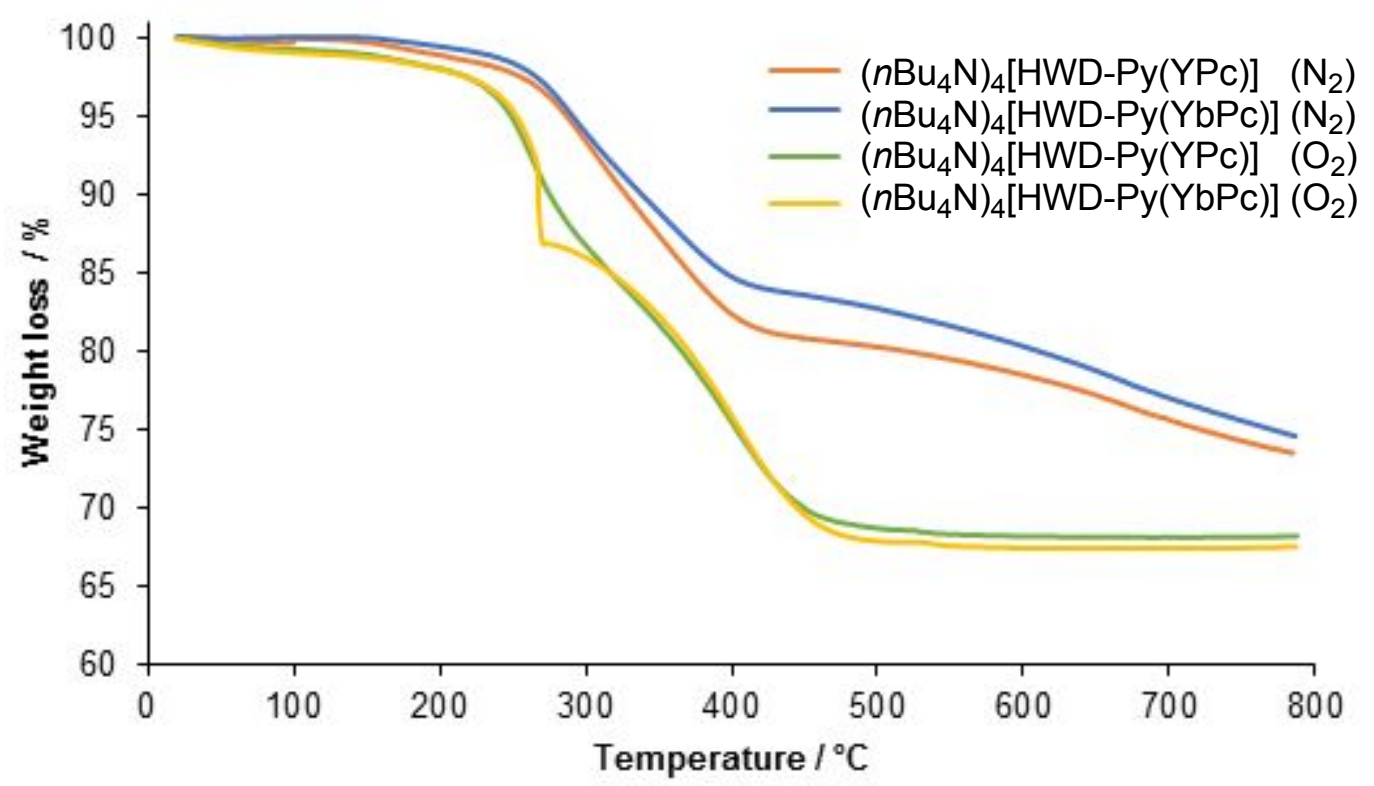

Figure S11. TGA curves of $\left(n \mathrm{Bu}_{4} \mathrm{~N}\right)_{4}[\mathrm{HWD}-\mathrm{Py}(\mathrm{YPc})]$ and $\left(n \mathrm{Bu}_{4} \mathrm{~N}\right)_{4}[\mathrm{HWD}-\mathrm{Py}(\mathrm{YbPc})]$ obtained under nitrogen atmosphere and in dry air.

Table S2. Acquired TGA data for $\left(n \mathrm{Bu}_{4} \mathrm{~N}\right)_{4}[\mathrm{HWD}-\mathrm{Py}(\mathrm{YPc})]$ and $\left(n \mathrm{Bu}_{4} \mathrm{~N}\right)_{4}[\mathrm{HWD}-\mathrm{Py}(\mathrm{YbPc})]$.

\begin{tabular}{c|c|c|c}
\hline Compound & Fragments & $\begin{array}{c}\Delta \omega \% \\
(\text { exptl. })\end{array}$ & $\begin{array}{c}\Delta \omega \% \\
\text { (calcd.) }\end{array}$ \\
\hline HWD-Py(YPc) $\left(\mathrm{N}_{2}\right)$ & $-2 \mathrm{Et}_{2} \mathrm{O},-4\left(n \mathrm{Bu}_{4} \mathrm{~N}\right)$ & 18.46 & 18.87 \\
HWD-Py(YPc) $\left(\mathrm{O}_{2}\right)$ & $-2 \mathrm{Et}_{2} \mathrm{O},-4\left(n \mathrm{Bu} \mathrm{u}_{4} \mathrm{~N}\right)$, \\
$\mathrm{HWD}-\mathrm{Py}(\mathrm{YbPc})\left(\mathrm{N}_{2}\right)$ & $\left.-2 \mathrm{OCH}_{2}\right)_{3} \mathrm{CC}_{5} \mathrm{H}_{4} \mathrm{~N},-\mathrm{H},-\mathrm{Pc},-2 \mathrm{P}$ & 31.80 & 31.91 \\
$\mathrm{HWD-Py}(\mathrm{YbPc})\left(\mathrm{O}_{2}\right)$ & $-2 \mathrm{Et}_{2} \mathrm{O},-3\left(n \mathrm{Bu}_{4} \mathrm{~N}\right)$ & 15.02 & 14.50 \\
& $-\left(\mathrm{OCH}_{2}\right)_{3} \mathrm{CC}_{5} \mathrm{H}_{4} \mathrm{~N},-\mathrm{H},-\mathrm{Pc},-2 \mathrm{P}$ & 32.46 & 31.46 \\
\hline
\end{tabular}




\section{Cyclic voltammetry measurements}

The compounds $\left(n \mathrm{Bu}_{4} \mathrm{~N}\right)_{4}[\mathrm{HWD}-\mathrm{Py}(\mathrm{YPc})]$ and $\left(n \mathrm{Bu}_{4} \mathrm{~N}\right)_{4}[\mathrm{HWD}-\mathrm{Py}(\mathrm{YbPc})]$ could not be examined by cyclic voltammetry due to their decomposition upon mixing with electrolytes (tetraethylammonium hexafluorophosphate or tetra- $n$-butylammonium hexafluorophosphate) in acetonitrile or dichloromethane (Figure S12). This is probably due to instability of the coordinative M-pyridine bond in electrolytic solutions.

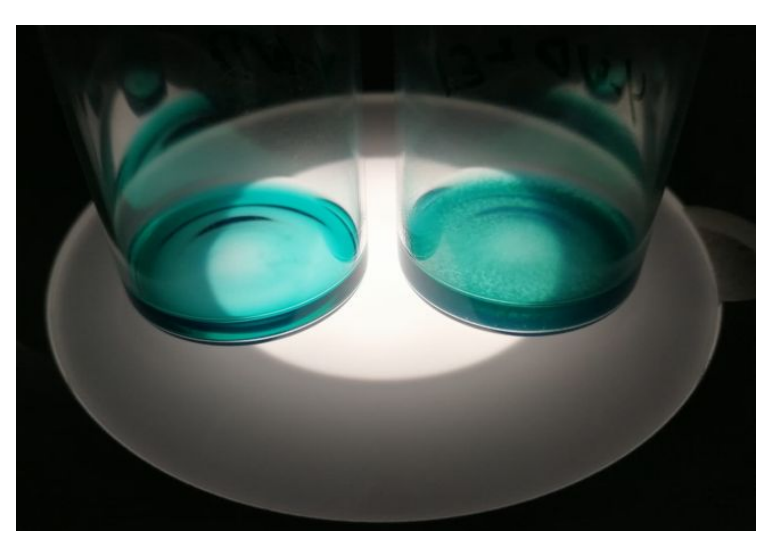

A

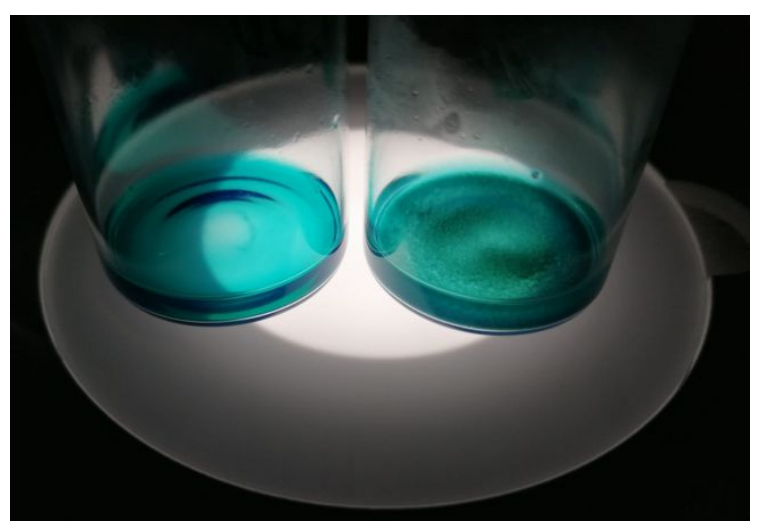

B

Figure S12. Solutions of $\left(n \mathrm{Bu}_{4} \mathrm{~N}\right)_{4}[\mathrm{HWD}-\mathrm{Py}(\mathrm{MPc})]\left(c=1 \times 10^{-3}\right)$ in acetonitrile without (each left) and with tetraethylammonium hexafluorophosphate $\left(c=1 \times 10^{-2}\right)$ ca. 10 seconds after addition (each right). $\mathrm{M}=\mathrm{Y}$ (image $\mathbf{A}$ ), $\mathrm{Yb}$ (image $\mathbf{B}$ ).

The electrochemical characteristics of $\mathrm{YPc}(\mathrm{OAc}) \cdot 2 \mathrm{MeOH}$ (Figure S13) and $\mathrm{YbPc}(\mathrm{OAc}) \cdot 2 \mathrm{MeOH}$ (Figure S14) are quite similar and their cyclic voltammograms do not display any apparent reversible redox processes. Weak irreversible oxidation waves at -1.11 $\mathrm{V}$ and $0.54 \mathrm{~V}$ for $\mathrm{YPc}(\mathrm{OAc}) \cdot 2 \mathrm{MeOH}$ and at $-1.04 \mathrm{~V}$ and $0.52 \mathrm{~V}$ for $\mathrm{YbPc}(\mathrm{OAc}) \cdot 2 \mathrm{MeOH}$ were observed. Additionally, irreversible reduction waves at $-1.35 \mathrm{~V}$ and $-1.22 \mathrm{~V}$ were assigned to yttrium and ytterbium phthalocyaninato complexes, respectively. 


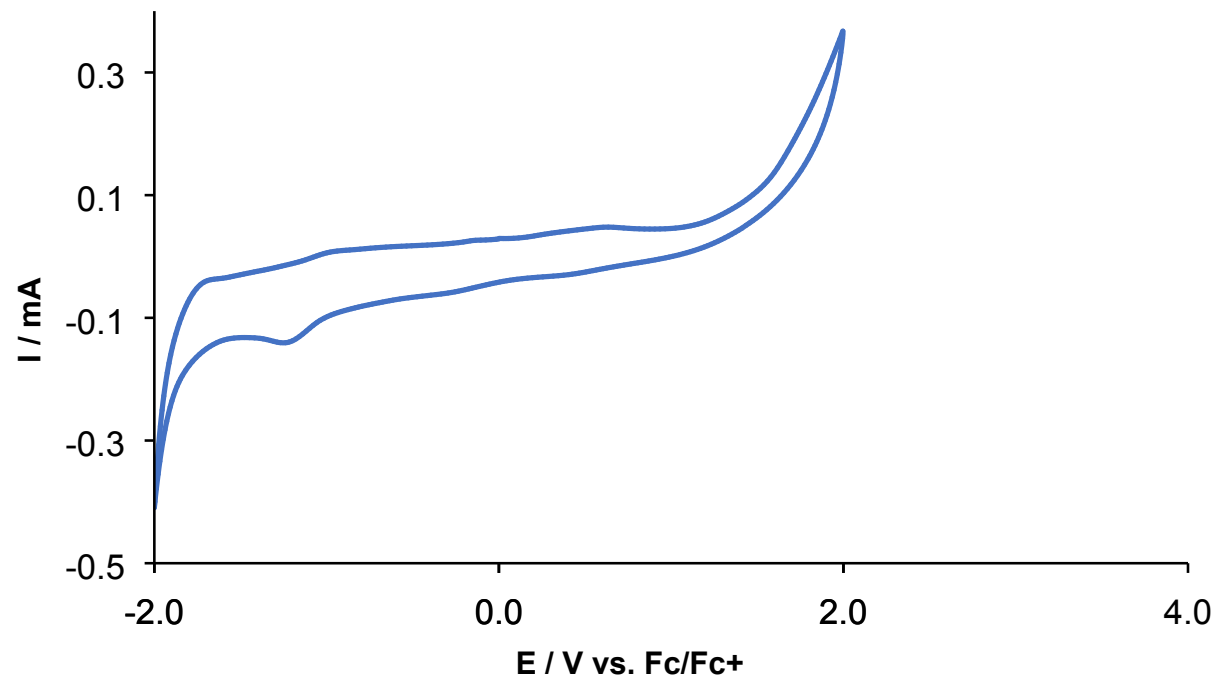

Figure S13. Cyclic voltammogram of $\mathrm{YPc}(\mathrm{OAc}) \cdot 2 \mathrm{MeOH}\left(c=1 \times 10^{-3}\right)$ in acetonitrile solution of tetraethylammonium hexafluorophosphate $\left(c=1 \times 10^{-1}\right)$. Scan rate $100 \mathrm{mV} \cdot \mathrm{s}^{-1} \mathrm{vs}$. Fc/Fct.

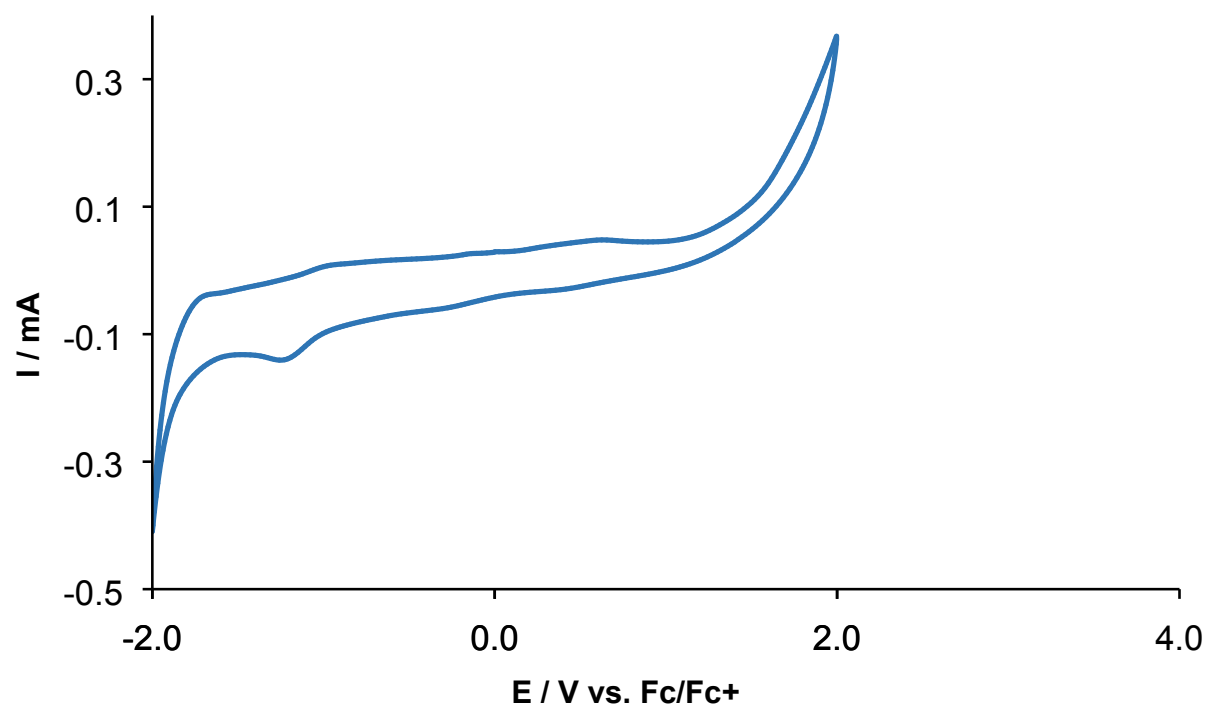

Figure S14. Cyclic voltammogram of $\mathrm{YbPc}(\mathrm{OAc}) \cdot 2 \mathrm{MeOH}\left(c=1 \times 10^{-3}\right)$ in acetonitrile solution of tetraethylammonium hexafluorophosphate $\left(c=1 \times 10^{-1}\right)$. Scan rate $100 \mathrm{mV} \cdot \mathrm{s}^{-1} \mathrm{vs}$. Fc/Fc'. 


\section{Magnetochemical modeling}

The magnetism of $\left(n \mathrm{Bu}_{4} \mathrm{~N}\right)_{4}[\mathrm{HWD}-\mathrm{Py}(\mathrm{MPc})] \quad(\mathrm{M}=\mathrm{Y}, \mathrm{Yb})$ has been modeled with different effective Hamiltonians, which were then fitted to the experimental data using evolutionary algorithms to minimize a fitting error:

$$
\Delta=\sqrt{\frac{1}{N} \sum_{i=1}^{N}\left(\frac{x_{i}^{e}-x_{i}^{t}}{x_{i}^{e}}\right)^{2}},
$$

where $N$ is the number of experimental points, and $x_{i}^{e}$ and $x_{i}^{t}$ stand for experimental and theoretical results, respectively. Susceptibility and magnetization have been calculated by diagonalizing effective Hamiltonians.

In the compound with $M=Y b$, the magnetism originates from the $Y b^{\prime \prime I}$ ion. Due to the strong spin orbit coupling it is sufficiently to consider only the lowest $J=7 / 2$ multiplet since the first excited multiplet lies circa $14000 \mathrm{~K}$ higher. ${ }^{4}$ Due to the same symmetry as in other phthalocyanine-containing POM compounds ${ }^{5}$ we use the same Hamiltonian:

$$
H_{Y b}=-\mu_{B} g_{\perp}\left(J_{x} B_{x}+J_{y} B_{y}\right)-\mu_{B} g_{\|} J_{z} B_{z}+D J_{z}^{2}
$$

where the anisotropic $g$-factor has the diagonal elements $\left(g_{\perp}, g_{\perp,} g_{\|}\right)$. The $z$-axis goes through $\mathrm{Yb}$ and $\mathrm{P}$ ions, $\mu_{\mathrm{B}}$ stands for Bohr magneton, $J_{\alpha}(\alpha=x, y, z)$ are components of $J=$ $7 / 2$ total angular momentum operator, and $\boldsymbol{B}=\left(B_{x}, B_{y}, B_{z}\right)$ stands for the magnetic field. Higher order anisotropic terms have also been considered, but they did not improve the quality of the fits. Since measurements were made for a powder sample and the molecule is highly anisotropic the theoretical results have been averaged over possible orientations of the magnetic field with respect to molecular axes. To this end for each value of $T$ (for susceptibility) and $B$ (for magnetization) 400 orientations of the magnetic field vector uniformly distributed over the hemisphere have been considered. For the best fit $\Delta=1.66 \%$.

In the compound with $M=Y$, the $Y^{I I I}$ ion is not magnetic. The obtained EPR spectra indicate the existence of unpaired electrons, both of radical organic character and localized at vanadium ions. The linear increase of magnetic susceptibility with temperature implies a possible contribution from temperature independent paramagnetism (TIP) or a strong antiferromagnetic interaction. Small saturation value of magnetization in high magnetic field suggests a strong dilution of magnetically active molecules. Therefore, in this case the following effective Hamiltonian is considered:

$$
H_{Y}=p_{2} K \boldsymbol{S}_{\mathbf{1}} \cdot \boldsymbol{S}_{\mathbf{2}}-p_{1} g \mu_{B} B S_{3}^{Z}-p_{2} g \mu_{B} B\left(S_{1}^{Z}+S_{2}^{Z}\right)
$$

where $S_{i}(i=1,2,3)$ stands for $S=1 / 2$ spin operator and $g=2.0014$. In addition to the value of susceptibility calculated from Hamiltonian (2) a constant value of $X_{\text {TIP }}$ has been added to account for TIP effect. For the same reason the magnetization was enlarged by the value of 
$X_{\mathrm{TIP}} B /\left(N_{\mathrm{A}} \mu_{0} \mu_{\mathrm{B}}\right)$. The parameters $p_{1}$ and $p_{2}$ stand for the fraction of the molecules that host, respectively, one and two unpaired electrons. In the case of the molecules hosting 2 unpaired electrons an exchange interaction of strength $K$ between the electrons is assumed. Parameters $p_{1}, p_{2}, K$ and $X_{\mathrm{TIP}}$ have been obtained by fitting the experimental data. The results are presented in Table S3 and Figures S15 and S16. Scenarios correspond to the following situations: 1 - no TIP, 2 - at most one unpaired electron for a molecule (no exchange interactions), 3 - only antiferromagnetic exchange interactions, 4 - no constraints. It has been checked, that taking into account anisotropic values of $g$ found for VIV ions causes only very small changes to the parameters in Table S3, which lead to no visible changes in Figures S15 and S16.

Table S3. Optimal parameters obtained by fitting Hamiltonian 2.

\begin{tabular}{|c|c|c|c|c|c|}
\hline Scenario & $X_{\mathrm{TIP}} / 10^{-8}\left[\mathrm{~m}^{3}\right]$ & $K / k_{B}[\mathrm{~K}]$ & $p_{2}$ & $p_{1}$ & $\Delta[\%]$ \\
\hline 1 & 0 & 137 & 0.48 & 0.34 & 20.2 \\
\hline 2 & 2.067 & 0 & 0 & 0.32 & 17.2 \\
\hline 3 & 1.53 & 11.8 & 0.094 & 0.29 & 13.4 \\
\hline 4 & 2.01 & -217 & 0.13 & 0.0006 & 10.5 \\
\hline
\end{tabular}

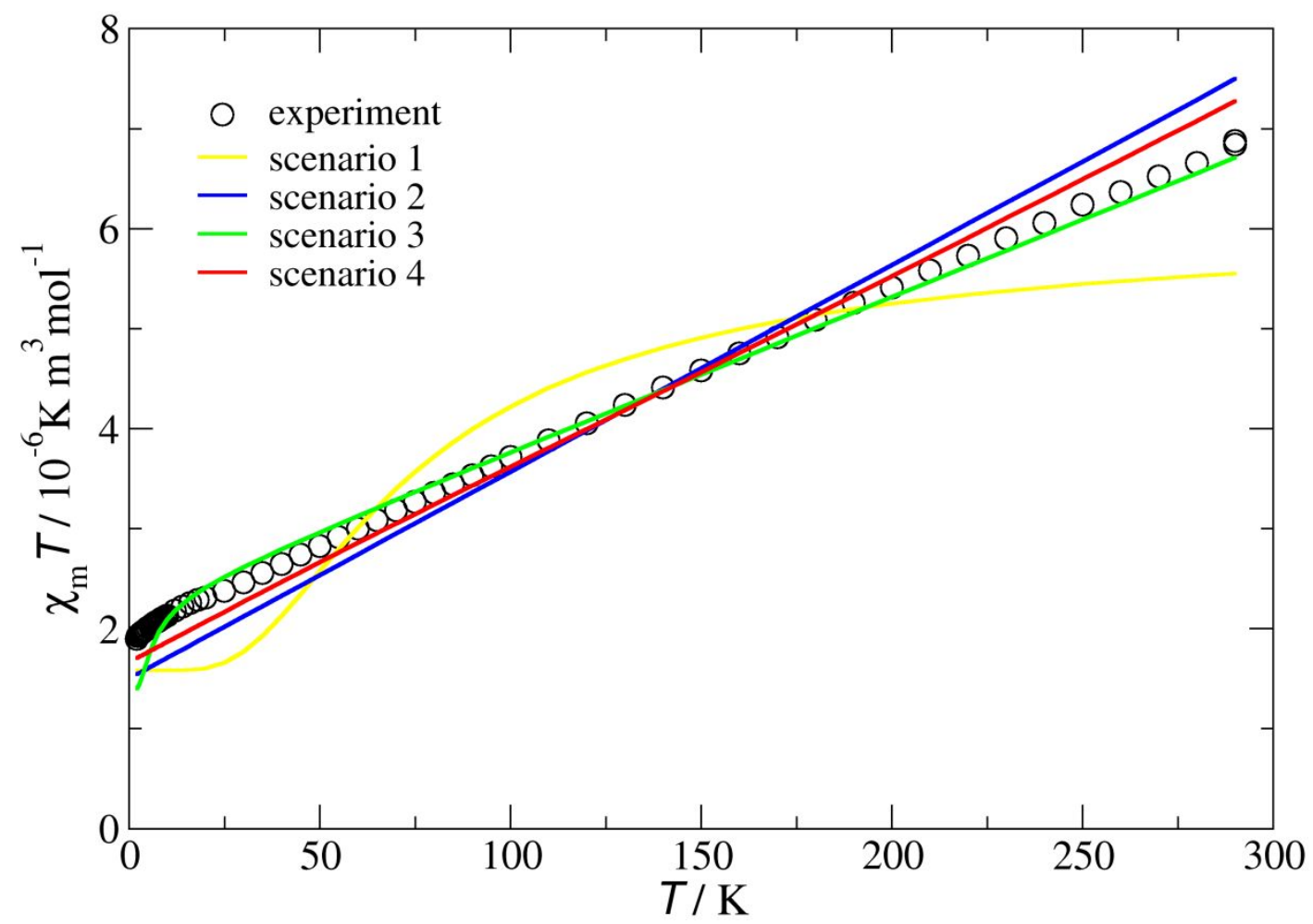

Figure S15. Molar susceptibility $(B=0.1 \mathrm{~T})$ of $\left(n \mathrm{Bu}_{4} \mathrm{~N}\right)_{4}[\mathrm{HWD}-\mathrm{Py}(\mathrm{YPc})]$ for different scenarios. 


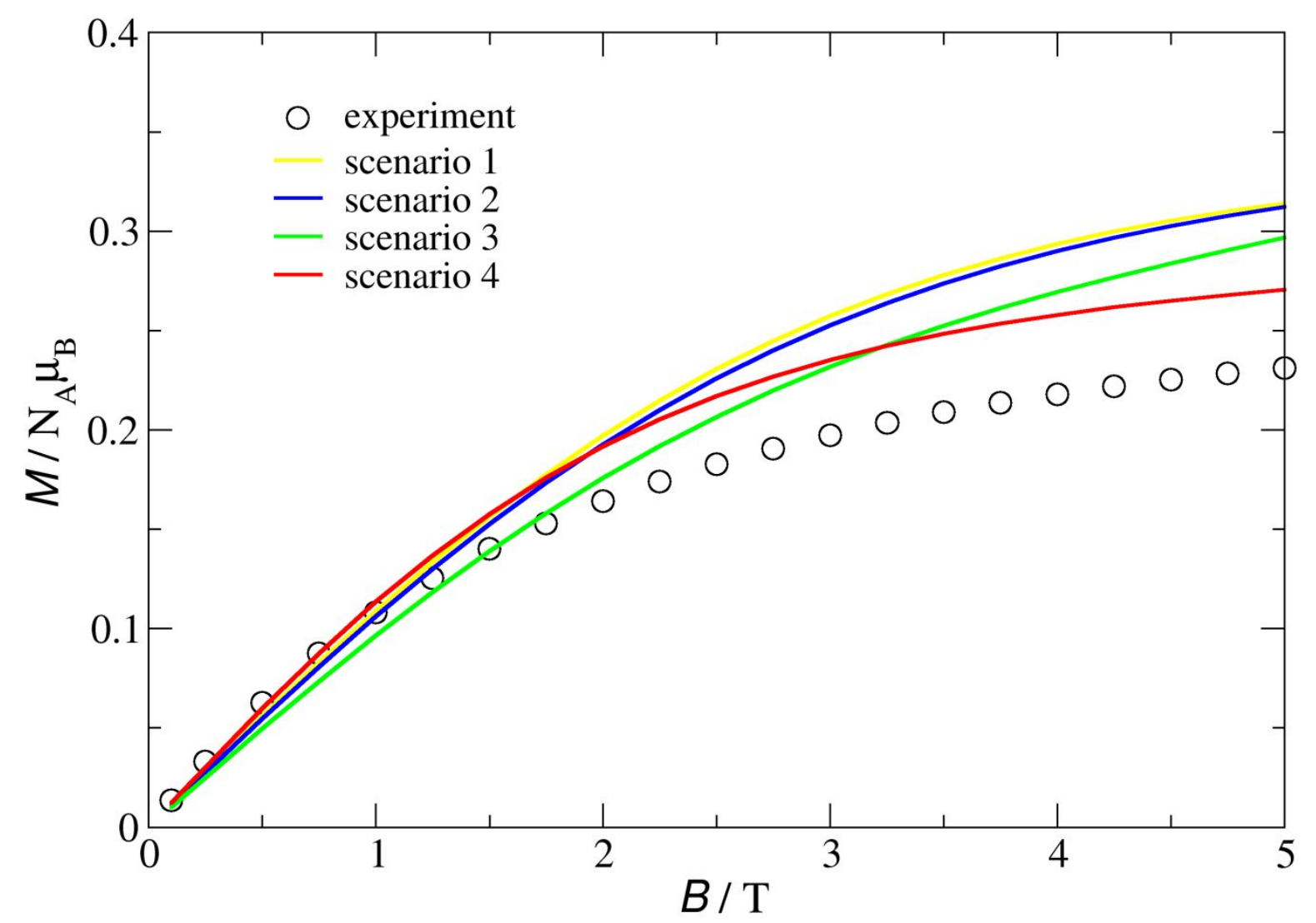

Figure S16. Magnetization $(T=2 \mathrm{~K})$ of $\left(n \mathrm{Bu}_{4} \mathrm{~N}\right)_{4}[\mathrm{HWD}-\mathrm{Py}(\mathrm{YPc})]$ for different scenarios.

The best result has been obtained in scenario 4 . However, this solution has two issues:

I. If two interacting electrons are located at the same molecule then it would suggest that the dimer formation and electron transfer between the molecules is not responsible for the magnetic behavior of this compound, which seems to contradict solution EPR and ESI-MS results.

II. If two interacting electrons are located at two molecules (in a dimer) then the strong ferromagnetic interaction seems rather improbable.

Big errors in fitting procedures which come mostly from the fit to magnetization indicate a need for a more refined model. Interestingly both, magnetization and susceptibility can be fitted very well, but separately. For magnetization the optimal parameters are close to those in scenario 4 and for susceptibility to scenario 3. 


\section{References}

(1) Finke, R. G.; Rapko, B.; Saxton, R. J.; Domaille, P. J. J. Am. Chem. Soc. 1986, 108, 2947.

(2) Linnenberg, O. Lindqvist-Hexavanadat-basierte organisch-anorganische Hybridmaterialien als molekulare Schalter, Doktorarbeit, RWTH Aachen, Verlagshaus Mainz $\mathrm{GmbH}, 2019$.

(3) Warneke, J.; Dülcks, T.; Knapp, C.; Gabel, D. Phys. Chem. Chem. Phys. 2011, 13, 5712-5721.

(4) Dieke, G. H. Spectra and Energy Levels of Rare Earth lons in Crystals. Wiley, New York, 1968.

(5) Pütt, R.; Qiu, X.; Kozłowski, P.; Gildenast, H.; Linnenberg, O.; Zahn, S.; Chiechi, R. C.; Monakhov, K. Y. Chem. Commun. 2019, 55, 13554-13557. 